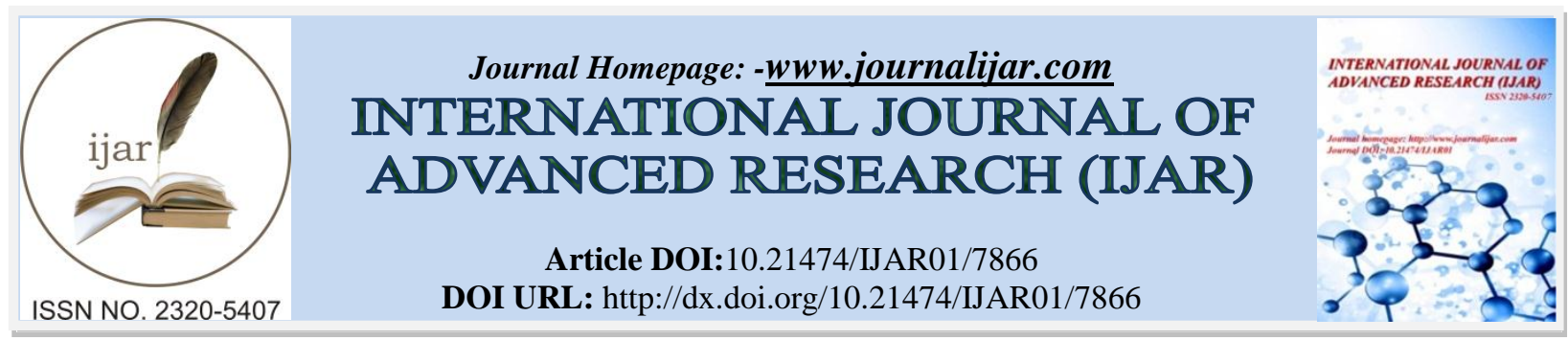

RESEARCH ARTICLE

\title{
FACTORS INFLUENCING OUTCOME OF ENDOVASCULAR TREATMENT OF ILIAC ARTERY DIEASES-INSTITUTIONAL EXPERIENCE.
}

\author{
Dr. D. Saravanan, Dr. K. Elancheralathan, Dr. C. Shanmugavelayutham and Dr. B. Deepankumar. \\ Department of vascular surgery,govt stanley medical college Chennai.
}

\section{Manuscript Info}

\section{Manuscript History}

Received: 9 August 2018

Published: October 2018

Keywords:-

endovascular treatment, iliac occlusive disease, critical limb ischemia, incapacitating claudication, major amputation.
Final Accepted: 11 September 2018

\begin{abstract}
Background: Endovascular treatment of iliac artery disease is well established in literature.Use of stents \&balloons in iliac artery disease has achieved long-term limb salvage and patency rates similar to those of open surgery, with lower morbidity\&mortality rates

Aims\&Objectives: To report outcomes, limb salvage and patency rates, of endovascular treatment for iliac artery diseases.

Materials \& methods

Patients admitted in our govt institution, suitable for endovasular intervention who underwent iliac angioplasty or stenting, Patients with critical limb ischemia or incapacitating claudication were included. In total, 49 IA procedures were performed in 42 patients, with an initial technical success rate of $91 \%$. fifteen angioplasty ,eight stenting fourteen angioplasty with stenting done and five bilateral angioplasty ,two bilateral stenting done. The follow-up was 12 months with the clinical assessment of pain, wound healing,ABI and Doppler.

Results: Mean age was 62 years.All patients were males, The indications were incapacitating claudication in 15 cases and rest pain or ulcer in 23 cases .The primary patency is $87 \%$, limb salvage is $92 \%$,ulcer healing $95 \%$, ABI improvemment $86 \%$, one mortality,three amputation seen.

Conclusions: we conclude that endovascular treatment of iliac artery disease is safe, is associated with satisfactory and reproducible longterm outcomes, and has a low perioperative mortality rate, the majority of patients with iliac occlusive disease can be safely treated with percutaneous endovascular procedures,patency comparable to open intervention . Patients not on follow up, continue to smoke, drug defaulter have increased the risk for amputation
\end{abstract}

Copy Right, IJAR, 2018,. All rights reserved.

\section{Introduction:-}

Treatment of iliac occlusive disease (IOD) has undergone substantial changes in the last few years. Previously, most treatment guidelines recommended endovascular intervention for single, short, and focal lesions, and open surgery for extensive iliac occlusive disease. However, with recent improvements in technology and endovascular techniques, guidelines are now advocating endovascular treatment instead of open surgery as the primary treatment for focal or extensive disease.(1,2)Use of stents in iliac angioplasty has also achieved long-term limb salvage and patency rates similar to those of open surgery, but with much lower morbidity and mortality rates.(3) 
The purpose of this paper is to report the long-term outcomes, focusing on limb salvage and patency, of endovascular treatment for iliac artery diseases and the factors associated with these outcomes in a single center.

\section{Methods:-}

1. This prospective study included consecutive patients with iliac artery disease who underwent iliac angioplasty at dept of vascular surgey, govt Stanley medical college hospital, between aug 2016 and aug 2018 Data obtained included the patient's general and demographic characteristics and information Details of the surgical procedures recorded

2. Patients with critical limb ischemia or incapacitating claudication who underwent iliac angioplasty during the index period were eligible for the study. Patients who experienced an initial technical failure were excluded from the study. In our department, we prefer to use bare-metal stents for iliac angioplasty. Patients are given $300 \mathrm{mg}$ of clopidogrel as a loading dose immediately after the procedure, and continue taking $75 \mathrm{mg}$ of clopidogrel per day for 6 months after surgery and aspirin (100 mg/day) for life. All patients receive some type of statin before and after surgery. The indications for angioplasty were based on prior reports, such as TASC I, II. $(4,5)$

3. Initial technical success of iliac angioplasty was defined as residual stenosis of $\leq 30 \%$, no dissection after the procedure, and prompt restoration of blood flow in the previously stenotic or occluded artery.

4. All the patients were followed-up via outpatient visits at the following times after discharge: 15 days, 1 month, 3 months, 6 months, 12 months, and every 6 months thereafter. The following information was recorded at each visit: pulse palpation, ankle-brachial index (ABI), and symptoms. Whenever possible, we also performed surveillance with arterial duplex ultrasonography at 1, 3, 6, and 12 months after surgery, and every 6 months thereafter. If any clinical or sonographic changes were noted, the case was discussed at a departmental meeting to assess whether re-intervention was required. Occlusion of the treated artery was defined, based on duplex.

5. The primary outcome variable was limb salvage. Major amputation was defined as amputation proximal to the ankle. The secondary outcome variables were patency, survival, and operative mortality. ultrasonography, as no flow, segmental, or complete.

6. In total, 49 iliac angioplasties were performed in 46 patients, with an initial technical success rate of $91 \%$ of patients Technical failure occurred in four patients, and was due to failure to progress a 0.035 " guidewire through the lesion. These patients were excluded from the analysis, leaving 42 patients and 49 aortoiliac angioplasties The excluded patients were treated with open revascularization procedures, one with aortofemoral bypass and other three with iliofemoral bypass.

7. The general characteristics of the patients are shown in Table 1 perioperative data are listed in table 2 endovascular procedures are summarized in table 3

Table 1:-Clinical Characteristics Of Patients

\begin{tabular}{|l|c|}
\hline \multicolumn{1}{|c|}{ Variable } & Value \\
\hline Age, years & $<50=11 \%(5)$, \\
& $50-60=38 \%(16)$ \\
& $>60=50 \%$ \\
\hline male & $42(100 \%)$ \\
\hline Hypertension & $16(38 \%)$ \\
\hline Diabetes mellitus & $36(85 \%)$ \\
\hline Heart disease & $2(4 \%)$ \\
\hline Chronic kidney failure & $4(8 \%)$ \\
\hline Tobacco use & $35(79.5 \%)$ \\
\hline Alcoholic & $23(54 \%)$ \\
\hline
\end{tabular}

Table 2:-Perioperative Data

\begin{tabular}{|l|c|}
\hline \multicolumn{1}{|c|}{ Variable } & Value \\
\hline Disabling claudication & $15(35 \%)$ \\
\hline Pain at rest & $10(23 \%)$ \\
\hline Trophic Lesion & $13(30 \%)$ \\
\hline postamputee & $4(8 \%)$ \\
\hline Perioperative mortality rate & $1(2 \%)$ \\
\hline
\end{tabular}




\begin{tabular}{|l|c|}
\hline Puncture site hematoma & $4(8 \%)$ \\
\hline Puncture site bleeding & $1 \quad(2 \%)$ \\
\hline
\end{tabular}

Table 3:-Endovascular procedures

\begin{tabular}{|l|c|}
\hline Variable & Value \\
\hline Limb treated Right & $21(50 \%)$ \\
\hline Left & $16(38 \%)$ \\
\hline b/l & $5(11 \%)$ \\
\hline Artery puncture site & $32(76 \%)$ \\
\hline Ipsilateral retrograde femoral artery & $4(9 \%)$ \\
\hline Contralateral retrograde femoral artery & $6(14 \%)$ \\
\hline B/L & \\
\hline Arteries inolved & $22(52 \%)$ \\
\hline Common iliac & $6(14 \%)$ \\
\hline External iliac & $10(23 \%)$ \\
\hline Common iliac + external iliac & $1(2 \%)$ \\
\hline Aorta + common iliac & 15 \\
\hline angioplasty & 8 \\
\hline Stenting & 14 \\
\hline Angioplasty \& stenting & 5 \\
\hline b/l angioplasty & 2 \\
\hline b/l stenting & \\
\hline
\end{tabular}

Fig 1,2,3:-rt iliac angioplasty
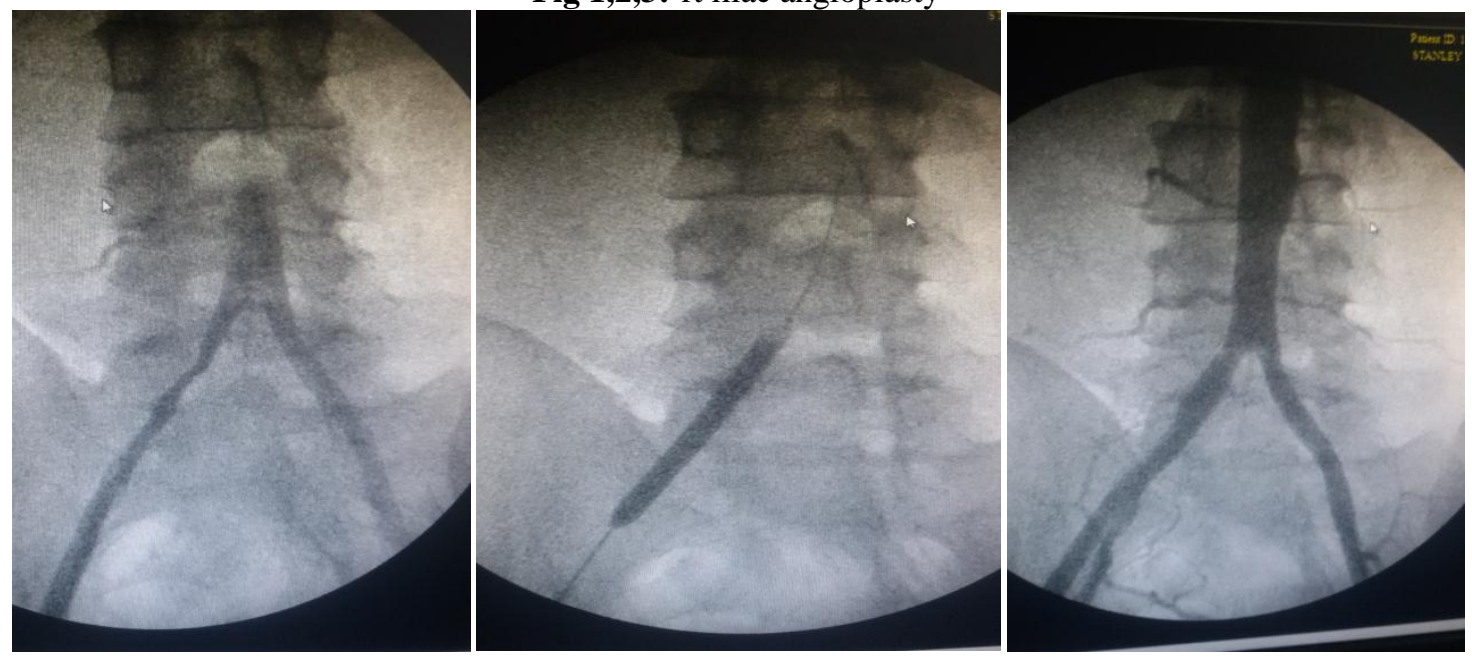

Fig 4,5,6:-b/l iliac stenting
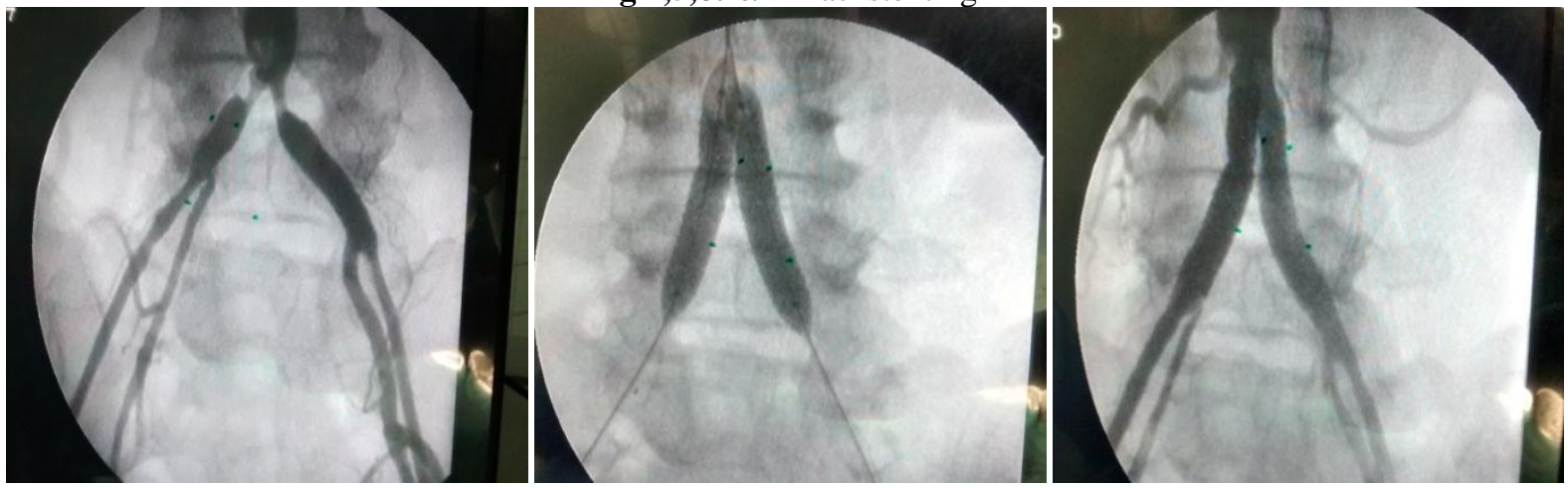


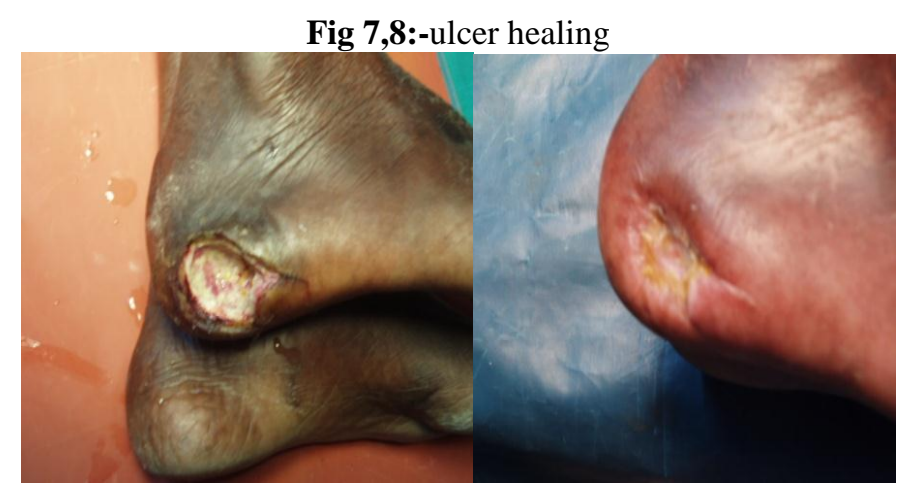

\section{Discussion \& Results:-}

Based on our study male sex with DM \&HT , Those smoking alcoholic having high risk for PAD, right side more than left involved trophic lesion is commonest presentation, common iliac artery mostly involved, cannulated with ipsilateral retrograde technique.. The mean ABI was greater after surgery than before surgery.

Technical success rate is $91 \%$, primary patency is $(87 \%)$,limb salvage $(92 \%)$, ulcer healing $95 \%$,ABI improvement $86 \%$ three patients required reintervention, endovascular surgery in one patients, iliofemoral bypass surgery in one patients ,and femorofemoral bypass in one .mortality in one patient due to sudden MI postoperatively

Factors associated with loss of limb patency

Restenosis or occlusion seen in six patients, among four more than $60 \mathrm{yrs}$, had critical limb threatening ischemia, four patient had chronic kidney disease,five of them smoker

\begin{tabular}{|l|l|}
\hline Age & $<60=2,>60=4$ \\
\hline Critical limb threatening ischemia & $6 / 6$ \\
\hline CKD & $4 / 6$ \\
\hline Smoker & $5 / 6$ \\
\hline
\end{tabular}

Patients with renal insufficiency(66\%) and critical limb threatening ischemia,(100\%) smoker(83\%) have increased risk for reduced primary patency rates after iliac artery stenting/angioplasty

\section{Factors associated with reintervention}

Reintervention done in three patients, all off them had critical limb threatening ischemia, diabetic,not on follow up ,continue to smoke,drug defaulter. Diabetic, missed followup,drug defaulter may have increased risk for reintervention...

\section{Factor associated with amputation}

Three amputation done ,all are drug defaulter,smoker.Drug defaulter (100\%), CKD (100\%), continue to smoke have increased risk for amputation...

Kudo et al. analyzed the long-term outcomes and predictors of outcome after iliac angioplasty in 151 patients. In that study, the cumulative primary patency rates at 1 , and 3years were $76 \%, 59 \%$, respectively. They reported that significant independent predictors for adverse outcomes were smoking history, TASC type C/D lesions, and stenosis of the ipsilateral superficial femoral artery for the primary patency rates. Meanwhile, chronic kidney failure with hemodialysis $(\mathrm{p}=0.014)$, ulcer/gangrene as an indication for percutaneous transluminal angioplasty were associated with adverse outcomes.(6)

Jongkind et al.(7) performed a systematic review of 19 nonrandomized cohort studies involving a total of 1711 patients who underwent endovascular treatment of extensive IOD. The mortality rate ranged from 1.2 to $6.7 \%$. The 1- or 2-year primary patency rate ranged from 70 to $86 \%$ In the present study, the estimated primary patency, limb salvage, at one year were $87 \%, 92 \%$, respectively These rates are similar to those reported in the literature described above. 
Galaria and associates reported 10-year patencies for patients with TASC A and B lesions(8)Indications for intervention were claudication $(77 \%)$ or critical ischemia (23\%). Altogether, 276 patients (all men; average age, 64 \pm 11 years; range, 32-87 years) underwent 394 interventions. Sixty-two percent of the lesions were TASC type A, and the remainder were type B. Of the 394 primary interventions, $51 \%$ included the placement of stents. Technical success (defined as $<30 \%$ residual stenosis) was achieved in $98 \%$ of treated vessels. The procedure-related mortality rate was $1.8 \%$ at 30 days and $4.7 \%$ at 90 days; the procedure-related complication rate was $7 \%$. Hemodynamic success (defined as a rise in the ABI >0.15) was achieved in $82 \%$. The average baseline Society for Vascular Surgery symptom score was $3.4+0.9$, which improved to $1.9 \pm 0.8$ following intervention. Within 3 months, $84 \%$ of patients demonstrated clinical improvement. Limb salvage rates were $95 \% \pm 2$ and $87 \% \pm 9$ at 5 and 10 years, respectively. By Cox proportional hazards analysis, hypertension, hypercholesterolemia, and chronic renal insufficiency were associated with increased risk of primary failure, whereas the presence of immediate hemodynamic improvement was associated with increased long-term patency. Stent use did not influence outcome. These results approach those reported for surgical aortoiliac bypass grafting. For comparison, in a meta-analysis of 23 studies of aortoiliac or aortofemoral bypass grafts published between 1970 and 1996, de Vries and Hunink calculated limb-based patency rates of $91 \%$ and $86.8 \%$ at 5 and 10 years, respectively, for patients with claudication, and patency rates of $88 \%$ and $82 \%$, respectively, for patients with critical ischemia(9).

In a prospective follow-up study of more than 550 patients with CLTI, $21.9 \%$ of patients were deceased after 1 year, and $31.6 \%$ after 2 years. 10 The overall incidence of cardiovascular death was $34.5 \%$, compared with $8.5 \%$ of deaths resulting from nonvascular causes. These numbers, based on large series, are well reflected in the our small population study of patients undergoing endovascular treatment for iliac occlusive disease.

This study has some important limitations to report.short term study with limited no of cases, those having health insurance, all case done by only by using c ARM, no cath lab facility available ..

\section{Conclusion:-}

Based on the results of this study, we conclude that endovascular treatment of IOD is safe, is associated with satisfactory and reproducible long-term outcomes, and has a low perioperative mortality rate,patency comparable to open surgery. Increasing age, smoker, diabetic, ckd, CLI associated with increased risk for reintervention \& amputation.

\section{References:-}

1. S. Sixt, A.K. Alawied, A. Rastan, U.S. Schwarzwalder, M. Kleim, E. Noory, et al.Acute and long-term outcome of endovascular therapy for aortoiliac occlusive lesions stratified according to the TASC classification: a single-center experience J Endovasc Ther, 15 (2008), pp. 408-416

2. C.D. Leville, V.S. Kashyap, D.G. Clair, J.F. Bena, S.P. Lyden, R.K. Greenberg, etal.Endovascular management of iliac artery occlusions: extending treatment to TransAtlantic Inter-Society Consensus class C and D patients J Vasc Surg, 43 (2006), pp. 32-39

3. et al. Clinical outcomes of 5358 patients undergoing direct open bypass or endovascular treatment for aortoiliac occlusive disease: a systematic review and meta-analysis.

4. J Endovasc Ther. 2013;20(4):443-455 Norgren L, Hiatt W, Dormandy J, et al. Inter-Society Consensus for the Management of Peripheral Arterial Disease (TASC II) Eur J Vasc Endovasc Surg. 2007;33(Suppl 1):S5-75.

5. Norgren L, Hiatt WR, Dormandy JA, et al. Inter-society consensus for the management of peripheral arterial disease (TASC II) J Vasc Surg. 2007;45(1):S5-67.

6. Kudo T, Chandra FA, Ahn SS. Long-term outcomes and predictors of iliac angioplasty with selective stenting. J Vasc Surg. 2005;42(3):466-475

7. Jongkind V, Akkersdijk GJ, Yeung KK, Wisselink W. A systematic review of endovascular treatment of extensive aortoiliac occlusive disease. J Vasc Surg. 2010;52(5):1376-1383.

8. Galaria II, Davies MG. Percutaneous transluminal revascularization for iliac occlusive disease: long-term outcomes in transatlantic inter-society consensus a and b lesions. Ann Vasc Surg. 2005;19:352-360.

9. de Vries SO, Hunink MG. Results of aortic bifurcation grafts for aortoiliac occlusive disease: a meta-analysis. $J$ Vasc Surg.1997;26:558-569.

10. 10. Dormandy J, Heeck L, Vig S. Peripheral arterial occlusive disease: clinical data for Introduction. Semin Vasc Surg. 1999;12:95.

decision making. 